\title{
A little toleration, please
}

Christopher McKnight The Queen's University of Belfast, Belfast

\begin{abstract}
Value pluralism does not imply relativism or subjectivism about values. What it does is allow respect for an at least limited toleration of values with which one may profoundly disagree. Thus a doctor can respect the autonomy of a patient whose values he does not share.

(Fournal of Medical Ethics 2000;26:432-434)

Keywords: Pluralism; multiculturalism; relativism; subjectivism; patient autonomy
\end{abstract}

John Catherwood's paper, A plea for intolerance, ${ }^{1}$ raises many (perhaps too many?) questions. His primary target is pluralism, particularly multicultural pluralism. He makes things easier for himself, however, by including in his attack other doctrines such as relativism and subjectivism without always clearly distinguishing them from pluralism. One can defend pluralism, as the writings of Isaiah Berlin, ${ }^{23}$ in particular make clear, without having to defend an "anything goes" version of liberalism which seems indistinguishable from relativism.

Catherwood describes pluralism's impact on medical practice as follows: "Since medicine is a science in the service of society, it is often suggested that we must respect the treatment choices that patients make in the light of their religious or cultural backgrounds". "Some version of the popularly revered Principle of Respect for Autonomy", he continues, "is usually wheeled out, along with venerable examples involving Jehovah's Witnesses or Christian Scientists. Two important features of these examples are usually stressed: that the individual practitioner's autonomy and moral judgments are not as important as those of the patient and that the patient's opinion has this overwhelming weight because of the cultural background that forms this opinion."

This sounds wrong. Ordinary doctor-patient contact cannot be represented as an encounter between an isolated individual practitioner and a mighty patient whose views, since they are backed by the whole force of his community are bound to prevail. Doctor and patient meet as individuals, but the doctor too is part of a community and if, as is likely, he or she is a member of the majority community his or her views should carry at least as much weight. If then we still hold that the patient's view must prevail this must be for reasons other than a commitment to communitarianism and multiculturalism.

Multiculturalism, however, and its associated pluralism are Catherwood's targets. His main weapon is something called "Western analytic philosophy". This is somewhat curious since he quotes with apparent approval MacIntyre's claim that at least in the area of moral philosophy this tradition has left behind a complete mess. None the less, this is what is needed to attack moralities and moral theories of which we disapprove. "I see no harm", he writes, "in allowing those skilled in the Western analytic philosophical tradition free rein in tackling the opinions and traditions of other cultures". But what leads him to think this will do any good? Whence the new-found optimism?

Together with a faith in Western analytic philosophy goes a faith in the ability of reason to resolve moral disputes and conflicts. Indeed one begins to suspect that he regards "reason" and "analytic philosophy" as near synonyms. He does, it is true, mention Bea Campbell's remark that analytic philosophy in general and logic in particular are "white boys' games" but seems to take no further notice of it and to assume that there is something neutral called "reason" whose authority will be recognised by all parties to a dispute whatever their social and cultural background and which has a good chance of resolving that dispute. But that is an assumption which pluralists are likely to deny and it is thus question-begging against them.

What exactly is this pluralism which Catherwood so dislikes? His targets include as well as pluralism, moral scepticism, subjectivism and relativism and he goes some way towards distinguishng them. "A more sophisticated stance", he says, "is that of the pluralist who claims not that there are no right and wrong answers, merely that there may be more than one right answer. Further sophistication may lead pluralists to point out that there may be many wrong answers as well." Having distinguished them from pluralism, however, he tends to concentrate his fire on relativism and subjectivism which are of course easier targets. And what he does say about pluralism does not always ring true. "Again", he writes, "the difficulty for the multicultural pluralist is that one culture's wrong answers are another culture's traditional imperatives". I fail to see yet why this is a difficulty. The next sentences may enlighten me: "Simply saying that both are correct, and demanding that each show tolerance does not 
resolve the dispute. Moreover it seems too hasty to assume that all or any traditional answers will be correct". But pluralists, if they are sensible, do not say that this is always the correct reaction only that it sometimes is. The pluralist's slogan is not "anything goes" but rather "several things go" "Anything goes" is more redolent of relativism and subjectivism and what is meant to be an attack on pluralism looks more like an attack on them. What follows is even worse: "To be involved in a multicultural disagreement only shows that at least one of us must be wrong. ... However, this is not a reason to say either that we should do as the pluralist suggests by abandoning debate and accepting both views, or that we should reject all moral claims... ."But, in the first place a pluralist does not have to suggest the abandonment of debate and more importantly it begs the question against pluralism to assume that in any dispute at least one of the disputants must be wrong. That is simply an assertion of monism.

Catherwood has difficulty too with morality. In discussing relativism he says: "The moral relativist must assume that both cultures are putting forward different moral traditions. Unless we have already assumed moral subjectivism then this cannot be the case"... . But there is confusion here. "Moral" can be used as a neutral term to distinguish between, for example, moral discourse and biological. Its opposite is "non-moral" and its use is classificatory. "Moral" can also of course be a term of commendation, where its opposite is "immoral": "how can such an immoral person as Bertrand Russell claim to be a moral philosopher?" Once the confusion is sorted out there is no earthly reason why we should deny that opinions we think utterly immoral are none the less moral opinions as opposed to, for example, opinions about nuclear physics.

\section{Further trouble}

There is further trouble ahead. Catherwood makes the good pluralist point that: "This is not to say that our moral theory must lead us to expect that there is only one possible good action in every case. There may be several morally acceptable courses of action. ... However, these are not cases of dispute, as there are no conflicts of principle in play, and in those cases there is no reason not to respect the diversity of traditions that various cultures have evolved". Take the following example: I am involved in a discussion with someone who accepts the famous four principles, as I do myself. We agree on the content of those principles and we agree that in the case under discussion there is a conflict between autonomy and beneficence. We agree, let us further suppose, that there are clear cases where one principle overrides the other but this case is not one of them. After discussion I opt for autonomy and he plumps for beneficence. Both of us, let us suppose, being tolerant pluralistically minded people, agree that the other decision is just as rational and justifiable as our own. Is there no dispute here? Well we still disagree, however amicably. And there are certainly principles in play; they are not conflicting in the sense that mine conflict with his (they are the same principles) but they are principles which can and do conflict with each other.

\section{Weightliness}

How do we get from here to intolerance? At times, Catherwood seems to want to build intolerance into morality by definition. At one point he invokes the claim that moral judgments are universalisable. "Whatever the right thing is, it is taken to be universally applicable no matter what culture we may be a part of ... and the universalisability of moral judgments seems to be an important feature that cannot be abandoned." But the fact, if it is a fact, that universalisability is a feature of our moral judgments which grow out of our Western tradition does not mean that it must be a feature of other cultures rather than a further part of the "white boys' game". Even if universalisability does become a cross-cultural feature, perhaps as a result of stateimposed study of the writings of R M Hare, ${ }^{4-6}$ it is not likely to secure much in the way of resolution since supporters of the female circumcision which Catherwood (rightly) finds repellent will probably be only too happy to endorse its universal desirability while we presumably will continue to universalise the opposite judgment.

If universalisability does not yield intolerance, where is it to come from? "There is a good deal of dispute", Catherwood says, "about what might count as a moral principle, but if anything is to count as one of my moral principles it surely must be true that I cannot allow others to hold and act upon contrary principles without challenge. Moral claims have a weight and importance which demand we seek to impose them on others." So those who disagree with us are not even allowed to hold let alone act upon their principles but must be challenged (presumably more than just verbally). And if this is "what might count as a moral principle" it looks as if the claims are meant to be true by definition. But it is surely not a good idea to build intolerance into the very notion of what it is to be a moral principle; we want there to be space a least for the intelligibility of a position which allows me to hold principles without a commitment to forcing them on others. Nor does it seem a good idea to build weightiness into the concept of morality itself. I have a belief that one ought to help the Third World and also a belief that one ought not to take red wine with fish but my commitment to the second is much stronger than to the first. On the suggested account the gastronomic principle, since it is the weightier, would have a claim to being a moral principle while the claim of the second would be more dubious. But morality does not have to be something weighty and there are people (fully rational people) who consider other things more important.

"The elevation of tolerance", Catherwood thinks, "seems to rely on some corruption of the liberal principle of respect for individual freedom. The suggestion is that we ought to allow others to 
act in ways they think morally acceptable, even if we think them morally repugnant, because they are under a similar obligation to give us the same freedom". But this is surely not the standard liberal principle which is rather that we ought to allow them freedom, even though we know perfectly well that, coming from a different tradition they acknowledge no such reciprocal obligation and would be quite happy to impose their views on us, if they had the requisite strength.

The one possible justification for pluralist multiculturalism, it is suggested, is that it is a precondition of a harmonious and stable community. But Catherwood thinks even that is a chimera. Pluralist toleration can result not in agreement, but only in agreement to disagree which is not an adequate basis for social harmony. In fact he thinks toleration will make things worse since it inevitably leads to unresolved moral disputes, which carry with them a high emotional charge, and which we have no means of resolving. The claims are empirical ones of course and the proof of the pudding is in future eating, but I take leave to doubt both whether liberal toleration actually increases emotional tension and also whether agreement secured by the intolerant means advocated would lessen it; rather the opposite I would have thought. It may be that agreement to disagree is the best we can hope for in a pluralist society and that the price of aiming at something higher where that consists of an artificial agreement imposed on the minority from without might turn out to be too high to be morally acceptable.

There is an honourable tradition in Western ethical thought which distinguishes immorality from illegality and which resists the idea that morality and the law should be co-terminous. Those in this tradition may feel and feel strongly that some practices (hunting for one example or abortion for another) are morally wrong but not want to ban them by law. "We dislike what you are doing", they might say, "and wish you would stop, but we are not prepared to force you by law to do so, because we respect your tradition and its customs and your right to organise your own lives within limits". This is an attitude we might take even to female circumcision. The children concerned, we might reason, are going to have to live in that particular community anyway and may suffer rejection if they do not have the operation. The effect of banning the practice might also be to drive it underground, thus making it even more dangerous than it currently is. To the community we would say: "We deplore this practice and wish it would cease. We reserve the right to criticise it and expose abuses in the media. We have a right also to regulate it with rules requiring licensing of practitioners and health checks on operating conditions. We will not, however, make it illegal, though we have the power so to do, out of respect for your culture and traditions which are deeply bound up with your sense of identity".

How might we justify such tolerance? In philosophical theology there is a standard reply to the problem of the existence of evil in the world to the effect that a world in which agents can act freely to organise their own lives, though it will of necessity contain evil and immoral actions is none the less better than one in which that freedom is taken away. Whatever we think about the force of this theological reply, we could invoke a similar principle for social philosophy; a world in which communities are free within limits to live their own lives will of necessity include immoral practices but is none the less a better world than a Catherwoodian one where immorality is eliminated by force.

Christopher McKnight is Lecturer in Philosopy, Department of Philosophy, The Queen's University of Belfast, Belfast.

\section{References}

1 Catherwood J. A plea for intolerance. Fournal of Medical Ethics 2000;26: .

2 Berlin I. Vico and Herder. London: Hogarth Press 1976: 206-7.

3 Berlin I. The crooked timber of humanity. London: Fontana 1991: 11-12.

4 Hare RM. The language of morals. Oxford: OUP, 1952

5 Hare RM. Freedom and reason. Oxford: OUP, 1961.

6 Hare RM. Moral thinking. Oxford: OUP, 1980 